\title{
The incidence of lower respiratory tract infections and pneumococcal vaccination status in adults in flemish primary care
}

\author{
Tine De Burghgraeve $\mathbb{D}^{\mathrm{a}}$, Séverine Henrard $\mathbb{D D}^{\mathrm{b}}$, Bart Verboven ${ }^{\mathrm{a}}$, Gijs Van Pottelbergh ${ }^{\mathrm{a}}$, Bert Vaes ${ }^{\mathrm{a}}$ \\ and Catharina Mathej ${ }^{\mathrm{a}}$
}

academic Center for General Practice, Department of Public Health and Primary Care, KU Leuven, Leuven, Belgium; 'bnstitut de Recherche Santé Et Société, Woluwe-Saint-Lambert, Belgium

\begin{abstract}
Pneumococcal vaccination coverage of adults at risk for pneumococcal disease is below recommended levels. There is no observational data on pneumococcal vaccination and the incidence of lower respiratory tract infections in a general adult population. The current study had the objective to explore the incidence of lower respiratory tract infections and the pneumococcal vaccine coverage in function of age, influenza vaccination status and risk status, in Flanders, Belgium. We used data from Intego, ageneral practice-based morbidity registration network in Flanders (Belgium). We gathered data on pneumococcal vaccinations, influenza vaccination (in 2014) and ICPC2-coded diagnoses of pneumonia and acute bronchitis (2015). First, we divided the population into three groups along the risk status for developing apneumococcal infection according to the recommendations for pneumococcal vaccination in adults by the Belgian High Council of Health. $28.6 \%$ from our total adult study population are considered the target group for vaccination. Second, we found that the average pneumococcal vaccination coverage in this targeted population was $18.7 \%$. Third, we found asignificantly higher incidence of LRTI in patients previously vaccinated against pneumococcal disease and/ or influenza across the majority of subgroups. Pneumococcal vaccination coverage in Flanders is quantitatively low but observed to be qualitatively high in terms of reaching the most at risk population. Our findings are likely to be highly relevant to addressing future vaccination strategies in Flanders.
\end{abstract}

\section{KEYWORDS}

Lower respiratory tract infections; pneumonia; bronchitis; pneumococcal vaccination

\section{Background}

Acute lower respiratory tract infections (LRTI), usually divided into pneumonia and acute bronchitis, are a major cause of morbidity and mortality worldwide, accounting for $4.8 \%$ of all deaths in 2013 [1]. LRTIs can be caused by a variety of pathogens, either viral (like influenza) or bacterial.

Streptococcus pneumoniae (SP) is the most frequently isolated pathogen in LRTI [2] and the most prevalent bacterial etiology of community-acquired pneumonia (CAP) in the European adult population $[3,4]$. In the Belgian adult population, SP was found to be responsible for approximately $5 \%$ of serious LRTIs observed in primary care [5]. Furthermore, SP is responsible for approximately one-fifth of the fatal LRTI cases [3]. Pneumococcal pneumonia is estimated to be the cause of over one million deaths annually [6], granting it the highest mortality from all vaccine-preventable infectious diseases [7]. Up to a third of community-acquired pneumonia may be influenza related, due to bacterial coinfection or secondary bacterial pneumonia [8].

To prevent pneumococcal diseases in adults, two types of vaccines are available: the 23 -valent pneumococcal polysaccharide vaccine (PPV23) and the 13- valent pneumococcal conjugate vaccine (PCV13). Although proven effective in children, the efficacy of these vaccines in the prevention of pneumococcal pneumonia in adults is up until now the subject of debate $[9,10]$. However, a recent meta-analysis proved PPV23 effectiveness against invasive pneumococcal disease (IPD) and pneumococcal pneumonia [11]. Furthermore, results of CAPiTA, a randomized, double-blind, placebo-controlled trial in $>84,000$ older adults aged $\geq 65$ years, showed that the PCV13 was effective in preventing vaccine-type pneumococcal CAP, vaccine-type pneumococcal non-bacteremic (noninvasive) CAP and vaccine-type IPD [12].

The availability of this study has prompted some recommending bodies to adapt recommendations for pneumococcal vaccination in adults to include PCV13 into the adult vaccination recommendations. Therefore, in Belgium, the High Council of Health recommends since 2014 to vaccinate adults aged 50 years or older with an increased risk of pneumococcal infection with PCV13 followed by PPV23 with an interval of at least 8 weeks. Generally, the population is divided into a 'median risk' and a 'high risk' group, based on age and other host or 
environmental factors [13-15]. Furthermore, the High Council of Health also recommends vaccinating all adults between 65 and 85 years old [16]. However, in daily practice, and in contrast to routine childhood immunization, adult vaccination rates turn out to be low- [17-19] and high-quality evidence of effectiveness of this strategy in the targeted population remains limited to the prevention of IPD and pneumonia in select patient groups [20-25].

In Belgium data on pneumococcal vaccination coverage are scarcely available and not of recent date. Moreover, the available data do not allow to assess to what extent the population at high risk for pneumococcal infection is reached. In addition, populationbased data with regards to the incidence of LRTI are lacking. Therefore, it is not possible to estimate whether the defined risk groups indeed represent individuals at highest risk for LRTI.

Therefore, the current study had the objective to explore the incidence of LRTI and the pneumococcal vaccine coverage in function of age, influenza vaccination status and risk status, in Flanders, Belgium. A second objective was to explore if the persons that are identified as being at risk by the actual recommendations, really develop most LRTI's.

\section{Methods}

\section{General methods of Intego}

Data were obtained from Intego, a Flemish general practice-based morbidity registration network, based at the Academic Centre for General Practice at the University of Leuven [26]. All the information is routinely collected in the electronic health records by the general practitioner (GP) during daily practice. Currently, $111 \mathrm{GPs}$, all using the medical software program Medidoc ${ }^{\circledast}$, are collaborating in the Intego project. These GPs work in 49 practices evenly spread throughout Flanders, the northern part of Belgium. Patients in this registration network cover about $2 \%$ of the Flemish population. The Intego GPS prospectively and continuously register all new diagnoses together with new drug prescriptions, laboratory test results, vaccinations, and some background information (including sex and year of birth) using computer-generated keywords linked to codes. Using specially framed extraction software, new data were collected on a yearly basis from the computers of the participating GPs by a trusted third party and entered into a central database. Registered data were continuously updated, accumulating a history for each patient.

\section{Data selection}

For this study, we included all patients aged 18 years or older and used available data until 31 December 2015.

Pneumococcal vaccination status (ATC code J07AL01, J07AL02, J07AL52) was recorded. The date of the last vaccination was recorded as well. The years since the last vaccination were calculated as follows: day event - day last vaccination for people with an event in 2015 or 31/12/2015 - day last vaccination for people with no event in 2015. Flu vaccination status (ATC code J07BB) was recorded for the previous year (2014).

The incidence and relative rates of acute pneumonia (ICPC2 code R81) and acute bronchitis (ICPC2 R78) and pneumococcal vaccination status were calculated for 2015. Data regarding relevant morbidities of the patients included in Intego were extracted out of the Intego database using ICPC2 codes. Using these data, patients were categorized into 3 categories according to the Belgian High Council of Health: high-risk patients for developing a pneumococcal infection (immunocompromising conditions; including HIV, hematologic malignancies, and the use of glucocorticoids or immunosuppressants), median risk patients (immunocompetent patients with a history of chronic respiratory or cardiovascular disease, chronic liver disease, chronic kidney disease or chronic alcohol abuse) and low-risk patients (all the other patients in the yearly contact group of 2015). The yearly contact group is defined as all patients who contacted their GP at least once in that year, and as a consequence patients of which we have data. This is in contrast to the practice population, which also contains patients who did not contact the GP in that year. This is explained earlier [27].ICPC2 codes for the comorbidities are displayed in Appendix A.

\section{Statistical analysis}

Data were presented as numbers and percentages. RRs (risk ratios) were calculated by using univariate and multivariate log-binomial regression. Adjusted risk ratios (aRR) and corresponding 95\% confidence interval $(95 \% \mathrm{Cl})$ were calculated using $\mathrm{R}$ software version 3.1.3.

\section{Results}

\section{Population at risk for pneumococcal infection}

From a total study population of 100,484 , more than a quarter of the adult population and almost half of the patients aged 65 or older met at least one criterion for being considered at median risk for developing a pneumococcal infection (48.5\%) while 3.7\% were considered to be at high risk (Table 1). In total, $28.6 \%$ 
Table 1. Proportion of adult patients at risk in 2015 and age group (4 age groups) $(\mathrm{N}=100,484)$.

\begin{tabular}{|c|c|c|c|c|c|}
\hline Risk group & Total population & $18-49$ years & $50-64$ years & $65-84$ years & $85+$ years \\
\hline High risk group, $\mathrm{n}$ & 2089 & 636 & 663 & 707 & 83 \\
\hline \multicolumn{6}{|c|}{ Number of high risk group comorbidities } \\
\hline 1 & $2006(96.0)$ & $620(97.5)$ & $633(95.5)$ & $672(95.0)$ & $81(97.6)$ \\
\hline$\geq 2$ & $83(4.0)$ & $16(2.5)$ & $30(4.5)$ & $35(5.0)$ & $2(2.4)$ \\
\hline \multicolumn{6}{|c|}{ Number of high and median risk group comorbidities } \\
\hline 1 & $1062(50.8)$ & $461(72.5)$ & $345(52.0)$ & $237(33.5)$ & $19(22.9)$ \\
\hline 2 & $559(26.8)$ & $145(22.8)$ & $190(28.7)$ & $204(28.9)$ & $20(24.1)$ \\
\hline$\geq 3$ & $468(22.4)$ & $30(4.7)$ & $128(19.3)$ & $266(37.6)$ & $44(53.0)$ \\
\hline Median risk group, $\mathrm{n}$ & 23,916 & 6983 & 6440 & 8272 & 2221 \\
\hline \multicolumn{6}{|c|}{ Number of median risk group comorbidities } \\
\hline 1 & $16,746(70.0)$ & $6247(89.5)$ & $4731(73.5)$ & $4733(57.2)$ & $1035(46.6)$ \\
\hline 2 & $4440(18.6)$ & $618(8.9)$ & $1218(18.9)$ & $2037(24.6)$ & $567(25.5)$ \\
\hline$\geq 3$ & $2730(11.4)$ & $118(1.7)$ & $491(7.6)$ & $1502(18.2)$ & $619(27.9)$ \\
\hline Low risk patients, $\mathrm{n}$ & 74,479 & 45,205 & 17,152 & 6377 & 3953 \\
\hline
\end{tabular}

$\mathrm{n}=$ number of participants.

of the adult study population belonged to the target group for vaccination according to the Belgian High Council of Health (Table 1). Older people tended to have more risk factors for developing a pneumococcal infection in both the medium- and high-risk groups, although this was more pronounced in the high-risk group. The majority of the $85+$ group with high risk for developing a pneumococcal infection had even 3 or more morbidities that were considered as risk factors for developing a pneumococcal infection (Table 1).

The presence of a cardiovascular disease or cardiovascular complaint was the most prevalent morbidity in adults aged 65 or older in the medium-risk group (Appendix B). On the other hand, in the study population up until 64 years, respiratory illnesses were the main morbidity in the medium-risk group (Appendix B). The dominant reason for being a high-risk patient was the same in both age groups; the prescription of glucocorticoids or other immunosuppressants (Appendix B).

\section{Vaccination coverage}

In total, 5162 patients (5.1\% of the study population) received a previous pneumococcal vaccination with the polysaccharide vaccine (PPV23) and 598 patients received the conjugated vaccine (PCV13) $(0.6 \%)$ (data not shown). According to the recommendations of the Belgian High Council of Health, $18.7 \%$ of the targeted population was previously vaccinated while the vaccination coverage was $0.9 \%$ in the non-target population (all patients aged 18-49 and low-risk patients aged 50-65) (Table 2).

In the 50-64 year olds, the vaccination coverage ranged from $5.6 \%$ in the medium-risk group to $17.8 \%$ in the high-risk group. Whereas in the 65-84 year olds, vaccination coverage ranged from $26.5 \%$ to $34.0 \%$ in the medium and high-risk group, respectively. Within each risk group, the vaccination coverage increased with increasing number of morbidities (Table 2). In the oldest group, the number of years since the last pneumococcal vaccination was higher compared to younger age groups. The overall rate of previous influenza vaccination in 2014 in our database was $17.2 \%$. In our study population, vaccination coverage increased with increasing age and/or risk status. In each subgroup, more people were vaccinated against flu as compared to pneumococcal vaccination (Table 2).

\section{Incidence of LRTI}

In 2015, the incidence of LRTI in the total adult population increased with age and risk status (32.2\%o, 76.1\%o and $142.2 \%$ for low-, medium- and high-risk groups, respectively) (Table 3). Even more, the incidence of LRTI increased with the number of morbidities within each age and risk group (Table 3). The same results were found both for acute bronchitis and pneumonia (Figure 1).

A seasonal trend was observed in the number of people with a diagnosis of LRTI. The risk of developing LRTI increased in fall and winter, i.e., from September to February. The same trend was seen for the incidence of acute bronchitis, but for pneumonia, this trend was less pronounced (Figure 2).

\section{Incidence of LRTI according to pneumococcal vaccination status}

A difference was observed in LRTI incidence between people who were vaccinated for pneumococcal disease (120.2\%o - overall medium-risk group; $218.4 \%$ overall high-risk group) and those who did not receive a pneumococcal vaccination $(69.5 \%$ - overall medium-risk group; $124 \%$ - overall high-risk group) (data not shown).

The incidence of LRTI was higher in all low-, medium- and high-risk groups of people vaccinated in the last 5 years, compared to the non-vaccinated people (Table 3). The opposite (more LRTI in the nonvaccinated people) was observed in a few subgroups based on the number of comorbidities (50-64y highrisk group with 1 or 2 high or medium-risk factors; 65$84 y$ high-risk group with one high or medium-risk 
Table 2. Proportion of adult patients with a previous registered pneumococcal vaccination per age and risk group in 2015 $(\mathrm{N}=100,484)$ (4 age groups).

\begin{tabular}{|c|c|c|c|c|c|}
\hline \multirow[b]{2}{*}{ Age and risk groups } & \multicolumn{2}{|c|}{$\begin{array}{l}\text { Previous pneumococcal vaccination } \\
\mathrm{n}(\%)\end{array}$} & \multirow{2}{*}{$\begin{array}{l}\text { Years since the last pneumococcal } \\
\text { vaccination Median }\left[\mathrm{P}_{25} ; \mathrm{P}_{75}\right]\end{array}$} & \multirow{2}{*}{$\begin{array}{l}>1 \text { previous vacci- } \\
\text { nation } \mathrm{n}(\%)\end{array}$} & \multirow{2}{*}{$\begin{array}{l}\text { Flu vaccination in } \\
2014 \mathrm{n}(\%)\end{array}$} \\
\hline & PPV & PCV & & & \\
\hline \multicolumn{6}{|l|}{ 50-64 years } \\
\hline Low risk $(N=17,152)$ & $263(1.53)$ & $47(0.27)$ & $3.3[1.3 ; 5.2]$ & $69(0.40)$ & $2020(11.78)$ \\
\hline \multicolumn{6}{|c|}{$\begin{array}{l}\text { Number of median risk } \\
\text { group comorbidities }\end{array}$} \\
\hline 1 & $181(3.83)$ & $30(0.63)$ & $3.2[1.4 ; 5.1]$ & $52(1.10)$ & $1049(22.17)$ \\
\hline 2 & $80(6.57)$ & $17(1.40)$ & $3.2[1.1 ; 5.1]$ & $23(1.89)$ & $371(30.46)$ \\
\hline$\geq 3$ & $48(9.78)$ & $5(1.02)$ & $2.9[1.2 ; 4.4]$ & $19(3.87)$ & $202(41.14)$ \\
\hline \multicolumn{6}{|l|}{$\begin{array}{l}\text { Number of high risk } \\
\text { group comorbidities }\end{array}$} \\
\hline 1 & 79 (12.48) & $26(4.11)$ & $1.6[0.8 ; 4.0]$ & $22(3.48)$ & $204(32.23)$ \\
\hline$\geq 2$ & $10(33.33)$ & $3(10.00)$ & $2.0[0.4 ; 3.1]$ & $3(10.00)$ & $14(46.67)$ \\
\hline \multicolumn{6}{|l|}{$\begin{array}{l}\text { Number of high and } \\
\text { median risk group } \\
\text { comorbidities }\end{array}$} \\
\hline 1 & $30(8.70)$ & $9(2.61)$ & $1.6[1.0 ; 4.0]$ & $4(1.16)$ & $93(26.96)$ \\
\hline 2 & $32(16.84)$ & $10(5.26)$ & $1.8[0.7 ; 4.2]$ & $14(7.37)$ & $62(32.63)$ \\
\hline$\geq 3$ & 27 (21.09) & $10(7.81)$ & $1.2[0.8 ; 3.3]$ & $7(5.47)$ & $63(49.22)$ \\
\hline \multicolumn{6}{|l|}{$65-84$ years } \\
\hline Low risk $(N=6377)$ & $1180(11.42)$ & $118(1.14)$ & $3.3[1.4 ; 5.2]$ & $490(4.74)$ & $4055(39.25)$ \\
\hline Median risk $(N=8272)$ & $1951(23.59)$ & $237(2.87)$ & $3.3[1.2 ; 5.3]$ & $827(10.00)$ & $5137(62.10)$ \\
\hline \multicolumn{6}{|c|}{$\begin{array}{l}\text { Number of median risk } \\
\text { group comorbidities }\end{array}$} \\
\hline 1 & $965(20.39)$ & $101(2.13)$ & $3.2[1.2 ; 5.2]$ & $416(8.79)$ & $2732(57.72)$ \\
\hline 2 & $498(24.45)$ & $72(3.53)$ & $3.3[1.2 ; 5.2]$ & $202(9.92)$ & $1327(65.14)$ \\
\hline$\geq 3$ & $488(32.49)$ & $64(4.26)$ & $3.3[1.2 ; 5.9]$ & $209(13.91)$ & $1078(71.77)$ \\
\hline High risk $(N=707)$ & $219(30.98)$ & $21(2.97)$ & $3.1[1.2 ; 4.5]$ & $104(14.71)$ & $488(69.02)$ \\
\hline \multicolumn{6}{|l|}{$\begin{array}{l}\text { Number of high risk } \\
\text { group comorbidities }\end{array}$} \\
\hline 1 & $206(30.65)$ & $19(2.83)$ & $3.2[1.2 ; 4.5]$ & 98 (14.58) & $462(68.75)$ \\
\hline$\geq 2$ & $13(37.14)$ & $2(5.71)$ & $1.2[0.7 ; 3.1]$ & $6(17.14)$ & $26(74.29)$ \\
\hline \multicolumn{6}{|l|}{$\begin{array}{l}\text { Number of high and } \\
\text { median risk group } \\
\text { comorbidities }\end{array}$} \\
\hline 1 & $61(25.74)$ & $5(2.11)$ & $3.2[1.2 ; 4.1]$ & $25(10.55)$ & $147(62.03)$ \\
\hline 2 & $56(27.45)$ & $6(2.94)$ & $2.3[1.0 ; 3.4]$ & 32 (15.69) & $138(67.65)$ \\
\hline$\geq 3$ & $102(38.35)$ & $10(3.76)$ & $3.2[1.5 ; 5.2]$ & 47 (17.67) & $203(76.32)$ \\
\hline \multicolumn{6}{|l|}{$\geq 85$ years } \\
\hline Low risk $(N=3953)$ & $229(12.78)$ & $2(0.11)$ & $4.2[2.3 ; 8.1]$ & $116(6.47)$ & $485(27.06)$ \\
\hline Median risk $(N=2221)$ & $659(29.67)$ & $20(0.90)$ & $4.3[3.1 ; 8.1]$ & $320(14.41)$ & $1227(55.25)$ \\
\hline High risk $(N=83)$ & $25(30.12)$ & $1(1.20)$ & $4.1[2.2 ; 6.7]$ & $15(18.07)$ & $55(66.27)$ \\
\hline
\end{tabular}

$\mathrm{n}=$ number of participants; PPV = pneumococcal polysaccharide vaccine; PCV: pneumococcal conjugated vaccine.

factor; $\geq 85 y$ medium-risk group with just one comorbidity). However, these differences were less pronounced compared to the total risk groups.

\section{Incidence of lower respiratory tract infections according to influenza vaccination status}

Irrespective of pneumococcal vaccination status, having received an influenza vaccination was associated with a higher chance of developing an LRTI. In the nonvaccinated people against influenza aged $\geq 85$ years, we noticed no clear pattern between the vaccinated and non-vaccinated people for pneumococcal infection (Table 4).

\section{Discussion}

\section{Main findings}

This large observational population-based study of an adult primary care population aimed to provide insights into the size of the population considered at risk for pneumococcal disease according to the Belgian recommendations, their vaccination coverage, and relative incidences of LRTI. First, $28.6 \%$ of our total adult study population was considered the target group for vaccination. Second, the average pneumococcal vaccination coverage in the target population was $18.7 \%$ and increased with age and risk status. Influenza vaccination coverage was more than five times as high in some risk and age groups. On the other hand, only $0.9 \%$ of the non-target population was vaccinated against pneumococcal diseases. Third, a significantly higher incidence of LRTI was found in previously vaccinated (pneumococcal and/or influenza) patients across the majority of subgroups. 
Table 3. Incidence and relative risk of LRTI per age and risk group in 2015 according to pneumococcal vaccination status $(\mathrm{N}=100,484)$.

\begin{tabular}{|c|c|c|c|c|}
\hline \multirow[b]{2}{*}{ Age and risk groups } & \multicolumn{4}{|c|}{ Incidence of LRTI (acute bronchitis or pneumonia) } \\
\hline & aRR $[95 \% \mathrm{Cl})$ & No vacc. \%o & Vacc. \%o & Total \%o \\
\hline \multicolumn{5}{|l|}{$18-49$ years } \\
\hline Low risk $(N=45,205)$ & $0.36(0.20 ; 0.74)$ & 23.7 & 65.7 & 23.8 \\
\hline \multicolumn{5}{|l|}{ All people } \\
\hline \multicolumn{5}{|l|}{ Median risk $(N=6983)$} \\
\hline \multirow{2}{*}{\multicolumn{5}{|c|}{ High risk $(N=636)$}} \\
\hline & & & & \\
\hline All people & $0.94(0.40 ; 3.02)$ & 75.1 & 80.0 & 75.5 \\
\hline \multicolumn{5}{|l|}{$50-64$ years } \\
\hline \multicolumn{5}{|l|}{ Low risk $(N=17,152)$} \\
\hline All people & $0.45(0.32 ; 0.67)$ & 40.0 & 88.7 & 40.8 \\
\hline \multicolumn{5}{|l|}{ Median risk $(N=6440)$} \\
\hline All people & $0.48(0.37 ; 0.64)$ & 71.4 & 147.6 & 75.3 \\
\hline \multicolumn{5}{|c|}{ Number of comorbidities } \\
\hline 1 & $0.54(0.37 ; 0.81)$ & 65.9 & 123.1 & 68.3 \\
\hline 2 & $0.42(0.27 ; 0.69)$ & 81.3 & 195.4 & 89.5 \\
\hline$\geq 3$ & $0.64(0.34 ; 1.39)$ & 102.0 & 160.0 & 107.9 \\
\hline \multicolumn{5}{|l|}{ High risk $(N=663)$} \\
\hline All people & $0.79(0.51 ; 1.28)$ & 147.7 & 188.1 & 153.8 \\
\hline \multicolumn{5}{|c|}{ Number comorbidities } \\
\hline 1 & $0.79(0.51 ; 1.32)$ & 147.6 & 186.8 & 153.2 \\
\hline$\geq 2$ & $0.75(0.14 ; 5.03)$ & 150.0 & 200.0 & 166.7 \\
\hline \multicolumn{5}{|c|}{ Number of high and median risk group comorbidities } \\
\hline 1 & $1.17(0.45 ; 4.68)$ & 102.9 & 88.2 & 101.4 \\
\hline 2 & $1.04(0.53 ; 2.39)$ & 201.3 & 194.4 & 200.0 \\
\hline$\geq 3$ & $0.71(0.37 ; 1.49)$ & 206.2 & 290.3 & 226.6 \\
\hline \multicolumn{5}{|l|}{$65-84$ years } \\
\hline \multicolumn{5}{|l|}{ Low risk $(N=6377)$} \\
\hline All people & $0.81(0.65 ; 1.04)$ & 52.0 & 63.9 & 53.4 \\
\hline Median risk $(N=8272)$ & & & & \\
\hline All people & $0.73(0.64 ; 0.85)$ & 87.0 & 118.5 & 94.8 \\
\hline Number of comorbi & & & & \\
\hline 1 & $0.72(0.59 ; 0.90)$ & 76.6 & 106.1 & 82.8 \\
\hline 2 & $0.91(0.68 ; 1.23)$ & 96.7 & 106.3 & 99.2 \\
\hline$\geq 3$ & $0.72(0.55 ; 0.94)$ & 111.7 & 155.5 & 126.5 \\
\hline High risk $(N=707)$ & & & & \\
\hline All people & $0.63(0.46 ; 0.87)$ & 147.6 & 234.5 & 175.4 \\
\hline Number of comorbi & & & & \\
\hline 1 & $0.64(0.46 ; 0.90)$ & 145.7 & 226.4 & 171.1 \\
\hline$\geq 2$ & $0.53(0.15 ; 1.69)$ & 190.5 & 357.1 & 257.1 \\
\hline Number of high an & & & & \\
\hline 1 & $1.06(0.53 ; 2.41)$ & 137.1 & 129.0 & 135.0 \\
\hline 2 & $0.38(0.19 ; 0.74)$ & 96.6 & 254.2 & 142.2 \\
\hline$\geq 3$ & $0.72(0.47 ; 1.11)$ & 205.0 & 285.7 & 236.8 \\
\hline$\geq 85$ years & & & & \\
\hline Low risk $(N=3953)$ & & & & \\
\hline All people & $0.75(0.43 ; 1.45)$ & 39.1 & 51.9 & 40.7 \\
\hline Median risk $(N=2221)$ & & & & \\
\hline All people & $0.91(0.70 ; 1.2)$ & 95.8 & 105.3 & 98.6 \\
\hline Number of comorbi & & & & \\
\hline 1 & $1.13(0.71 ; 1.91)$ & 80.7 & 71.2 & 78.3 \\
\hline 2 & $0.81(0.48 ; 1.40)$ & 86.8 & 107.0 & 93.5 \\
\hline$\geq 3$ & $0.90(0.6 ; 1.37)$ & 132.4 & 146.9 & 137.3 \\
\hline High risk $(N=83)$ & & & & \\
\hline All people & $0.42(0.21 ; 0.83)$ & 193.0 & 461.5 & 277.1 \\
\hline Number of comorbi & & & & \\
\hline 1 & $0.43(0.21 ; 0.85)$ & 200.0 & 461.5 & 284.0 \\
\hline$\geq 2$ & NA & 0.0 & NA & 0.0 \\
\hline Number of high an & & & & \\
\hline 1 & NA & 0.0 & 250.0 & 52.6 \\
\hline 2 & NA & 176.5 & 333.3 & 200.0 \\
\hline$\geq 3$ & $0.61(0.28 ; 1.24)$ & 320.0 & 526.3 & 409.1 \\
\hline
\end{tabular}

$\mathrm{n}=$ number of participants; PPV = Pneumococcal polysaccharide vaccine; PCV: Pneumococcal conjugated vaccine: aRR $(95 \% \mathrm{Cl})=$ adjusted risk ratio $(95 \%$ confidence interval); vacc = vaccination; NA = Not applicable.

\section{Comparison of findings to literature}

\section{Vaccination coverage}

In 2005, the pneumococcal vaccination coverage in the Belgian older population was estimated to be $30 \%$ [28], compared to our $21.5 \%$ coverage of the 65
+ population (Table 2). More recently, data from a Belgian survey in the same region and year as our study reported a much lower pneumococcal vaccination coverage in the population at risk $(8.0 \%)$, but also observed a much higher influenza vaccination coverage (29\%) [29]. This was a survey in the general 
Table 4. Incidence and relative risk of LRTIs per age and risk group in 2015 according to pneumococcal vaccination status for people who had (no) influenza vaccination in $2014(\mathrm{~N}=83,247)$.

\begin{tabular}{|c|c|c|c|c|c|c|c|c|}
\hline \multirow[b]{2}{*}{ Age and risk groups } & \multicolumn{4}{|c|}{$\begin{array}{l}\text { Incidence of LRTI (acute bronchitis or pneumonia) For } \\
\text { people without influenza vaccination in } 2014\end{array}$} & \multicolumn{4}{|c|}{$\begin{array}{l}\text { Incidence of LRTI (acute bronchitis or pneumonia) For } \\
\text { people with influenza vaccination in } 2014\end{array}$} \\
\hline & aRR $[95 \% \mathrm{Cl})$ & $\begin{array}{l}\text { No pneumo } \\
\text { vacc. } \% \text { o }\end{array}$ & $\begin{array}{l}\text { Pneumo } \\
\text { vacc. } \% \text { o }\end{array}$ & $\begin{array}{c}\text { Total } \\
\% 0\end{array}$ & aRR $[95 \% \mathrm{Cl})$ & $\begin{array}{l}\text { No pneumo } \\
\text { vacc. } \% \text { o }\end{array}$ & $\begin{array}{l}\text { Pneumo } \\
\text { vacc. } \% 0\end{array}$ & $\begin{array}{c}\text { Total } \\
\% 0\end{array}$ \\
\hline \multicolumn{9}{|l|}{ 50-64 years } \\
\hline $\begin{array}{l}\text { All people } \\
\text { Median risk }(N=6440)\end{array}$ & $1.24(0.54 ; 3.96)$ & 38.5 & 31.0 & 38.4 & $0.39(0.26 ; 0.62)$ & 52.3 & 134.1 & 58.9 \\
\hline $\begin{array}{l}\text { All people } \\
\text { Number of median risk group } \\
\text { comorbidities }\end{array}$ & $0.37(0.25 ; 0.59)$ & 63.9 & 173.1 & 66.2 & $0.71(0.50 ; 1.05)$ & 96.8 & 136.0 & 102.3 \\
\hline 1 & $0.44(0.25 ; 0.89)$ & 61.1 & 138.5 & 62.5 & $0.74(0.45 ; 1.29)$ & 84.9 & 115.4 & 88.7 \\
\hline 2 & $0.30(0.15 ; 0.71)$ & 68.2 & 230.8 & 73.2 & $0.64(0.36 ; 1.26)$ & 116.1 & 180.3 & 126.7 \\
\hline$\geq 3$ & $0.38(0.16 ; 1.44)$ & 87.0 & 230.8 & 93.4 & $0.94(0.41 ; 2.68)$ & 127.3 & 135.1 & 128.7 \\
\hline \multicolumn{9}{|l|}{ High risk $(N=663)$} \\
\hline $\begin{array}{l}\text { All people } \\
\text { Number of high risk group } \\
\text { comorbidities }\end{array}$ & $0.44(0.24 ; 1.05)$ & 120.6 & 272.7 & 128.1 & $1.4(0.80 ; 2.61)$ & 230.2 & 164.6 & 206.4 \\
\hline 1 & $0.39(0.21 ; 0.92)$ & 117.4 & 300.0 & 125.9 & $1.55(0.87 ; 3.05)$ & 240.6 & 154.9 & 210.8 \\
\hline$\geq 2$ & NA & 214.3 & 0.0 & 187.5 & NA & 0.0 & 250.0 & 142.9 \\
\hline \multicolumn{9}{|l|}{$\begin{array}{l}\text { Number of high and median } \\
\text { risk group comorbidities }\end{array}$} \\
\hline 1 & $0.36(0.13 ; 2.00)$ & 90.2 & 250.0 & 95.2 & $3.88(0.8 ; 69.45)$ & 149.3 & 38.5 & 118.3 \\
\hline 2 & $0.48(0.21 ; 1.76)$ & 159.7 & 333.3 & 171.9 & $2.31(0.92 ; 7.57)$ & 342.9 & 148.1 & 258.1 \\
\hline$\geq 3$ & $0.83(0.21 ; 13.72)$ & 166.7 & 200.0 & 6169.2 & $0.88(0.40 ; 2.01)$ & 270.3 & 307.7 & 285.7 \\
\hline \multicolumn{9}{|l|}{$65-84$ years } \\
\hline \multicolumn{9}{|l|}{ Low risk $(N=6377)$} \\
\hline \multicolumn{9}{|l|}{ Median risk $(N=8272)$} \\
\hline \multicolumn{9}{|l|}{$\begin{array}{l}\text { Number of median risk group } \\
\text { comorbidities }\end{array}$} \\
\hline 1 & $0.55(0.37 ; 0.86)$ & 65.3 & 119.2 & 70.5 & $0.85(0.66 ; 1.09)$ & 87.2 & 103.0 & 91.9 \\
\hline 2 & $0.66(0.37 ; 1.29)$ & 83.5 & 126.4 & 88.7 & $1.04(0.75 ; 1.46)$ & 106.0 & 102.3 & 104.7 \\
\hline$\geq 3$ & $1.21(0.57 ; 3.11)$ & 99.7 & 82.2 & 96.7 & $0.70(0.52 ; 0.95)$ & 118.2 & 167.8 & 138.2 \\
\hline \multicolumn{9}{|l|}{ High risk $(N=707)$} \\
\hline \multicolumn{9}{|l|}{$\begin{array}{l}\text { Number of high risk group } \\
\text { comorbidities }\end{array}$} \\
\hline 1 & $0.28(0.14 ; 0.66)$ & 90.4 & 318.2 & 114.3 & $0.85(0.59 ; 1.24)$ & 183.8 & 215.8 & 197.0 \\
\hline$\geq 2$ & NA & 0.0 & 1000.0 & 111.1 & $1.00(0.29 ; 3.46)$ & 307.7 & 307.7 & 307.7 \\
\hline \multicolumn{9}{|l|}{$\begin{array}{l}\text { Number of high and median } \\
\text { risk group comorbidities }\end{array}$} \\
\hline 1 & NA & 132.5 & 0.0 & 122.2 & $0.97(0.44 ; 2.31)$ & 141.3 & 145.5 & 142.9 \\
\hline 2 & NA & 32.3 & 500.0 & 60.6 & $0.61(0.30 ; 1.25)$ & 144.6 & 236.4 & 181.2 \\
\hline$\geq 3$ & $0.16(0.05 ; 0.46)$ & 78.4 & 500.0 & 158.7 & $1.02(0.64 ; 1.64)$ & 263.6 & 258.1 & 261.1 \\
\hline \multicolumn{9}{|l|}{$\geq 85$ years } \\
\hline \multicolumn{9}{|l|}{ Median risk $(N=2221)$} \\
\hline \multicolumn{9}{|l|}{$\begin{array}{l}\text { Number of median risk group } \\
\text { comorbidities }\end{array}$} \\
\hline 1 & $1.14(0.45 ; 3.80)$ & 55.6 & 48.8 & 54.5 & $1.39(0.81 ; 2.55)$ & 113.1 & 81.1 & 101.7 \\
\hline 2 & $0.64(0.20 ; 2.40)$ & 38.5 & 59.7 & 44.2 & $0.98(0.56 ; 1.80)$ & 131.3 & 133.3 & 132.1 \\
\hline$\geq 3$ & $2.02(0.56 ; 12.81)$ & 65.1 & 32.3 & 56.3 & $0.92(0.61 ; 1.43)$ & 179.9 & 194.6 & 185.6 \\
\hline \multicolumn{9}{|l|}{ High risk $(N=83)$} \\
\hline \multicolumn{9}{|l|}{$\begin{array}{l}\text { Number of high risk group } \\
\text { comorbidities }\end{array}$} \\
\hline 1 & $0.37(0.06 ; 1.89)$ & 111.1 & 300.0 & 178.6 & $0.43(0.20 ; 0.90)$ & 243.2 & 562.5 & 339.6 \\
\hline$\geq 2$ & NA & NA & NA & NA & NA & 0.0 & NA & 0.0 \\
\hline \multicolumn{9}{|l|}{$\begin{array}{l}\text { Number of high and median } \\
\text { risk group comorbidities }\end{array}$} \\
\hline 1 & NA & 0.0 & NA & 0.0 & NA & 0.0 & 250.0 & 100.0 \\
\hline 2 & NA & 200.0 & NA & 200.0 & NA & 166.7 & 333.3 & 200.0 \\
\hline$\geq 3$ & $0.83(0.05 ; 4.70)$ & 250.0 & 300.0 & 285.7 & NA & 333.3 & 777.8 & 466.7 \\
\hline
\end{tabular}

$\mathrm{n}=$ number of participants; PPV = pneumococcal polysaccharide vaccine; PCV: pneumococcal conjugated vaccine: aRR $(95 \% \mathrm{Cl})=$ adjusted risk ratio $(95 \%$ confidence interval); vacc $=$ vaccination; $N A=$ not applicable.

population based on self-reported data. The Intego database is based on patient records completed by the physician. Surveys are more prone to nonresponder bias and errors because some people are not aware of which type of vaccine they received. The latter being a general concern in survey-based estimates of vaccination coverage. Therefore, the use of 


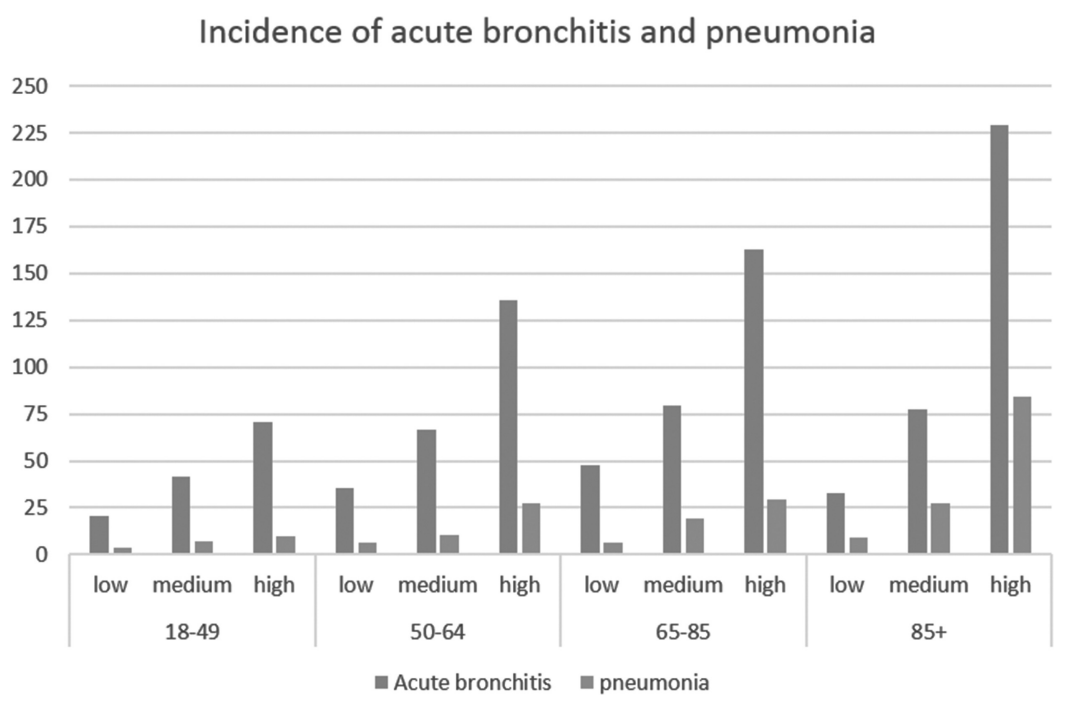

Figure 1. Incidence of acute bronchitis of pneumonia per age and risk group in $2015(N=100,484)$. Legend: Incidence of acute bronchitis of pneumonia in \%o per age and risk group in 2015. 4 age groups were used 18-49 years; 50-64 years; 65-85 years and $\geq 85$ year and 3 risk groups were used according to the recommendations of the Belgian high council of health. Figures were displayed in blue for acute bronchitis and orange for pneumonia.

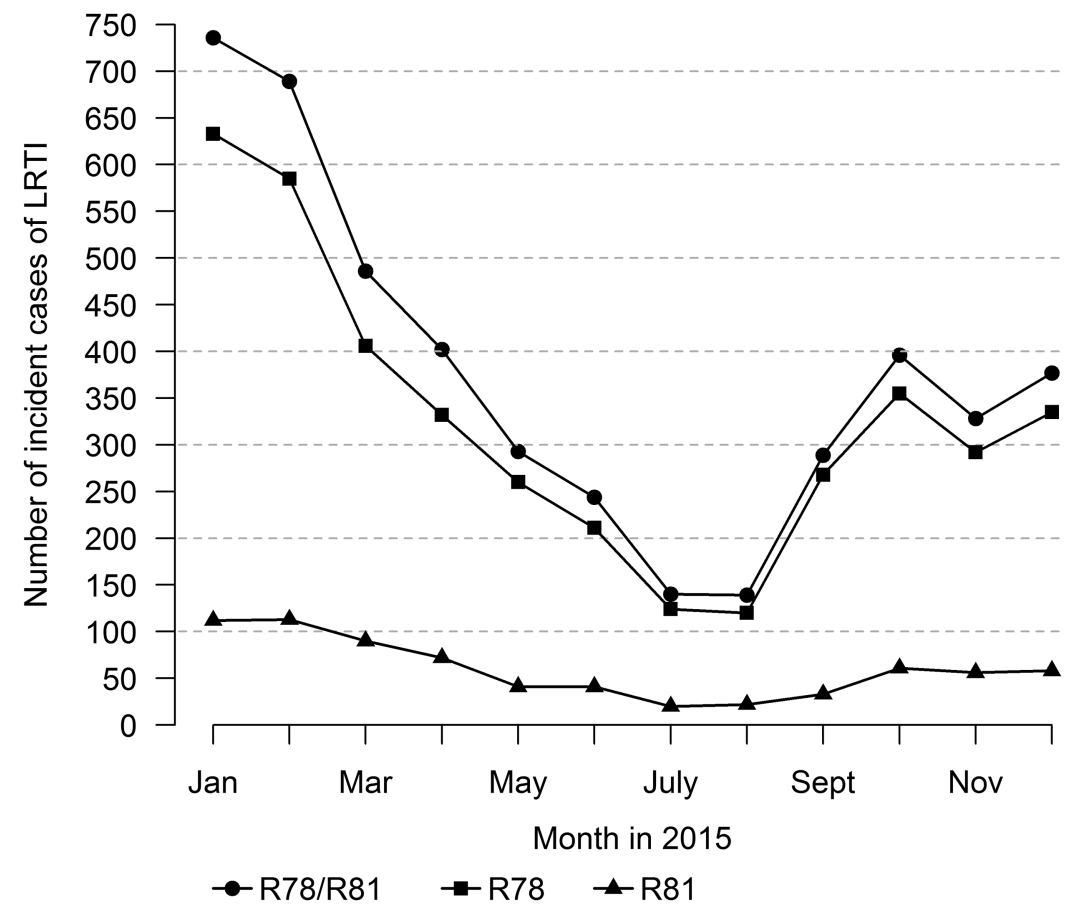

Figure 2. Number of people with a diagnosis of a lower respiratory tract infection in 2015 per month. Legend: Number of people with a diagnosis of a lower respiratory tract infection (circles), bronchitis (rectangles) of pneumonia (triangles) in 2015 were displayed per month.

medical record data was put forward as the golden standard [30-34].

While studies on pneumococcal vaccination rates in other Western countries also reported a low coverage of their targeted adult populations, they generally reported higher rates than our findings. Marked international differences, even within Europe, are attributable to the heterogeneity in guidelines defining different risk groups based on other criteria [35] or severity cut-off points [36], and their complex conjunction with vaccine uptake influencing factors such as vaccination programs and affordability or reimbursement [37].

\section{The incidence of $L R T I$}

Other large population-based observational studies of primary care records in different regions, also reported a higher incidence of LRTI according to predefined risk criteria. For example, in the Dutch population selected underlying conditions were related to a twofold increase in incidence of LRTI [38] which was much similar to our findings, and a threefold increase in risk for 
CAP in the U.S. population [15]. A population-based study in the U.K. confirmed our finding of an increased incidence of LRTI with age to be most noticeably for pneumonia [39]. We found an overall incidence of pneumonia in the Flemish population of 5.8/1000py, which seems fairly low according to reported incidences of 9.7/ 1000 py in Germany [40] and 10.6/1000py in subjects aged 18-64 years in the USA [41]. However, a summary of other research in Europe also showed a variety of incidence estimates [42].

\section{Effectiveness of pneumococcal/influenza vaccines} While the incidence of LRTI significantly increased with risk (comorbidities) and to lesser extent with age, we found a significantly higher incidence of LRTI in previously vaccinated patients with a pneumococcal and/ or influenza vaccine across the majority of subgroups. Based on these results, the vaccine apparently seemed inefficient. However, several remarks should be made in this context. The vaccine effectiveness (VE) should be monitored in observational cohort studies when the vaccine is already available in practice. However, multiple forms of bias/confounding have been described in observational cohort studies. Confounding by indication is likely to be present if patients with underlying chronic diseases are more likely to be vaccinated than healthy study participants. This leads to an underestimation of VE since the less healthy population is at higher risk of adverse health outcomes. This automatically implies a high risk of confounding by indication $[43,44]$. Furthermore, although SP is the most frequently isolated pathogen in LRTIs, only a limited proportion of $5 \%$ of the LRTIs is caused by pneumococcal infections. Third, along the recommendations, only adults from 50 years or more with comorbidities are advised to be vaccinated against pneumococcal disease. This may imply that, due to immunosenescence, there might be a lower uptake of the vaccine with increasing risk and/or age. For all these reasons we cannot make any conclusions on vaccine effectiveness.

\section{Strength and weaknesses}

Our study has important strengths, being a large, population-based study of 100,484 primary care records, covering approximately $2 \%$ of all adults spread throughout Flanders. Without the bias of non-responders and questionable accuracy of self-reported vaccination status, we were able to provide a more accurate estimate of vaccination coverage in the adult Flemish population than the current survey-based results [29].

While GPs in Flanders often diagnose pneumonia without radiological confirmation, we realize some diagnoses could be missed or false [45]. However, we argue to have substantially reduced this limitation by focusing on all LRTI; thus, still capturing diagnoses that could have switched after technical investigation.
Registration of smoking status in the Intego database is inadequate. Therefore, we could not use this important risk factor correctly in risk assessment [46]. However, as this would only rule out 'healthy smokers' because we would have detected smokers as soon as secondary pulmonary or cardiovascular conditions emerge. For the same reason, we could not adjust for socioeconomic factors, but these were shown to be of limited influence in the Belgian elderly population [47]. Gender is also known to be a potential risk factor [21] but again not of the utmost importance to our general study objective.

\section{Clinical impact}

We observed low vaccination coverage. The confirmation of a higher incidence according to risk and age supports the need for efforts to increase vaccination coverage in the target population. We suggest it could be pragmatically doubled through seasonal co-administration with the influenza vaccine, since influenza vaccination coverage was much higher in the target group.

On the other hand, we observed very low vaccination coverage of the non-target group. We can conclude that GPs in that respect comply with the guidelines. We observed a higher incidence of LRTI in the most vulnerable population who was already vaccinated. With this in mind, we observe that GPs can assign the most vulnerable people by using the guidelines. For this, we would not recommend to redefine the target group for vaccination.

\section{Conclusion}

This observational study of 100,484 primary care records was the first to explore the incidence of LRTI and the pneumococcal vaccination coverage in the general Flemish adult population according to age and risk criteria. From the perspective of not seeing a lower incidence of LRTI in vaccinated patients, we argue that - in line with findings in clinical trials - the protective effect of the pneumococcal vaccine in adults would be small at best in our observations. The results on vaccination coverage and incidence of LRTI according to risk and age might indicate the presence of a bias by indication, as seen in similar observational studies in other regions. The confirmation of a higher incidence according to risk and age supports the need for efforts to increase vaccination coverage in the target population.

\section{Availability of data}

Intego has no permission form the ethical review board to publish the full database. 


\section{Consent for publication}

Patients are well informed about Intego through posters in the waiting room of the GP's. They do not sign an informed consent but can use the opt-out option that is incorporated in the EHR of the GP. Data are pseudonymised and by no means have researchers access to names or contact details of the patients.

\section{Disclosure statement}

No potential conflict of interest was reported by the authors.

\section{Funding}

The Intego team was funded by the Flemish Agency 'Zorg en Gezondheid'. TDB and CM received funding from Pfizer, Belgium.

\section{ORCID}

Tine De Burghgraeve (D) http://orcid.org/0000-0002-05616504

Séverine Henrard (D) http://orcid.org/0000-0002-0389-8093

\section{Ethics approval and consent to participate}

Data were collected from the computers of the participating GPs by a trusted third party. The scientific and ethical review board assesses whether the questions are ethically correct (Ethics Board) and scientifically sound (Scientific Board). They have an advisory function, comparable to a Data Safety Monitoring Board in clinical trials. By this, our procedures are compliant with the law confirmed by decision $n^{\circ} 13.026$ of March 19th, 2013 of the Sectoral Committee of Social Security and Health (www.privacycommission.be). The Intego procedures were approved by the ethical review board of the Medical School of the Catholic University of Leuven (no ML 1723).

\section{Authors' Contributions}

BVB, GVP and CM conceived the study idea, SH was responsible for statistical analyses, TDB and BV took the lead in writing the manuscript. All authors discussed the results and contributed to the final manuscript.

\section{References}

[1] Vos T, Barber RM, Bell B, et al. Global, regional, and national incidence, prevalence, and years lived with disability for 301 acute and chronic diseases and injuries in 188 countries, 1990-2013: a systematic analysis for the global burden of disease study 2013. Lancet. 2015;386(9995):743-800.

[2] Macfarlane J, Holmes W, Gard P, et al. Prospective study of the incidence, aetiology and outcome of adult lower respiratory tract illness in the community. Thorax. 2001;56(2):109-114.

[3] Rozenbaum MH, Pechlivanoglou P, van der Werf TS, et al. The role of Streptococcus pneumoniae in community-acquired pneumonia among adults in Europe: a meta-analysis. Eur J Clin Microbiol Infect
Dis. 2013 Mar;32(3):305-316. PubMed PMID: 23242464; eng.

[4] Torres A, Peetermans WE, Viegi G, et al. Risk factors for community-acquired pneumonia in adults in Europe: a literature review. Thorax. 2013 Nov;68(11):1057-1065. PubMed PMID: 24130229; PubMed Central PMCID: PMCPMC3812874. eng.

[5] Flamaing J, De Backer W, Van Laethem Y, et al. Pneumococcal lower respiratory tract infections in adults: an observational case-control study in primary care in Belgium. BMC Fam Pract. 2015 May 27;16:66. 10.1186/s12875-015-0282-1. PubMed PMID: 26012956; PubMed Central PMCID: PMCPMC4443659. eng.

[6] Naghavi $M$, Wang $H$, Lozano $R$, et al. Global, regional, and national age-sex specific all-cause and cause-specific mortality for 240 causes of death, 1990-2013: a systematic analysis for the global burden of disease study 2013. Lancet. 2015;385(9963):117-171.

[7] WHO. 23-valent pneumococcal polysaccharide vaccine. WHO position paper. Wkly Epidemiol Rec. 2008 Oct 17;83 (42):373-384. PubMed PMID: 18927997; eng fre.

[8] Joseph C, Togawa Y, Shindo N. Bacterial and viral infections associated with influenza. Influenza Other Respir Viruses. 2013 Sep;7 Suppl 2:105-113. PubMed PMID: 24034494; eng.

[9] Jose RJ, Brown JS. Adult pneumococcal vaccination: advances, impact, and unmet needs. Curr Opin Pulm Med. 2017 May;23(3):225-230. PubMed PMID: 28198725; eng.

[10] Pitsiou GG, Kioumis IP. Pneumococcal vaccination in adults: does it really work? Respir Med. 2011 Dec;105 (12):1776-1783. PubMed PMID: 21816596; eng. .

[11] Falkenhorst G, Remschmidt C, Harder T, et al. Effectiveness of the 23-valent pneumococcal polysaccharide vaccine (PPV23) against pneumococcal disease in the elderly: systematic review and meta-analysis. PLoS One. 2017;12(1):e0169368. PubMed PMID: 28061505; PubMed Central PMCID: PMCPMC5218810. eng.

[12] Bonten MJ, Huijts SM, Bolkenbaas $M$, et al. Polysaccharide conjugate vaccine against pneumococcal pneumonia in adults. N Engl J Med. 2015 Mar 19;372(12):1114-1125. PubMed PMID: 25785969; eng.

[13] Torres A, Blasi F, Dartois N, et al. Which individuals are at increased risk of pneumococcal disease and why? Impact of COPD, asthma, smoking, diabetes, and/or chronic heart disease on community-acquired pneumonia and invasive pneumococcal disease. Thorax. 2015 Oct;70(10):984-989. PubMed PMID: 26219979; PubMed Central PMCID: PMCPMC4602259. eng.

[14] Said MA, Johnson HL, Nonyane BA, et al. Estimating the burden of pneumococcal pneumonia among adults: a systematic review and meta-analysis of diagnostic techniques. PLoS One. 2013;8(4):e60273. PubMed PMID: 23565216; PubMed Central PMCID: PMC3615022.

[15] Shea KM, Edelsberg J, Weycker D, et al. Rates of pneumococcal disease in adults with chronic medical conditions. Open Forum Infect Dis. 2014 Mar;1(1): ofu024. PubMed PMID: 25734097; PubMed Central PMCID: PMCPMC4324183. eng.

[16] Gezondheidsraad H. Vaccinatie tegen pneumokokken; 2014. Available from:

https://www.zorg-en-gezondheid.be/sites/default/ files/atoms/files/Vaccinatie\%20tegen\%20pneumokok ken $\% 20-\% 20$ volwassenen $\% 20 \% 282014 \% 29 \% 20 \%$ 28HGR\%209210\%29.pdf 
[17] Theidel U, Kuhlmann A, Braem A. Pneumococcal vaccination rates in adults in Germany: an analysis of statutory health insurance data on more than 850,000 individuals. Dtsch Arztebl Int. 2013 Nov 01;110(44):743-750. PubMed PMID: 24280430; PubMed Central PMCID: PMCPMC3831240. eng.

[18] Rouveix E, Gherissi Cherni D, Dupont C, et al. Streptococcus pneumoniae vaccinal coverage in hospitalized elderly patients in France. Med Mal Infect. 2013 Jan;43(1):22-27. PubMed PMID: 23246143.

[19] Lu PJ, Nuorti JP. Uptake of pneumococcal polysaccharide vaccination among working-age adults with underlying medical conditions, United States, 2009. Am J Epidemiol. 2012 Apr 15;175(8):827-837. PubMed PMID: 22403807; eng.

[20] Maruyama T, Taguchi O, Niederman MS, et al. Efficacy of 23-valent pneumococcal vaccine in preventing pneumonia and improving survival in nursing home residents: double blind, randomised and placebo controlled trial. BMJ. 2010 Mar 08;340:c1004. PubMed PMID: 20211953; PubMed Central PMCID: PMCPMC2834887. eng.

[21] Ochoa-Gondar O, Vila-Corcoles A, Rodriguez-Blanco T, et al. Effectiveness of the 23-valent pneumococcal polysaccharide vaccine against community-acquired pneumonia in the general population aged $\geq 60$ years: 3 years of follow-up in the CAPAMIS study. Clin Infect Dis. 2014;58(7):909-17.

[22] Schiffner-Rohe J, Witt A, Hemmerling J, et al. Efficacy of PPV23 in preventing pneumococcal pneumonia in adults at increased risk-a systematic review and meta-analysis. PloS One. 2016;11:1.

[23] Kraicer-Melamed H, O'Donnell S, Quach C. The effectiveness of pneumococcal polysaccharide vaccine 23 (PPV23) in the general population of 50 years of age and older: A systematic review and meta-analysis. Vaccine. 2016 Mar 18;34(13):1540-1550. PubMed PMID: 26899372; eng.

[24] Bonten MJ, Huijts SM, Bolkenbaas $M$, et al. Polysaccharide conjugate vaccine against pneumococcal pneumonia in adults. N Engl J Med. 2015;372 (12):1114-1125.

[25] Ewald H, Briel M, Vuichard D, et al. The clinical effectiveness of pneumococcal conjugate vaccines. Dtsch Arztebl Int. 2016 Mar 4;113(9):139-146. PubMed PMID: 26987462; PubMed Central PMCID: PMC4802351.

[26] Truyers C, Goderis G, Dewitte H, et al. The Intego database: background, methods and basic results of a Flemish general practice-based continuous morbidity registration project. BMC Med Inform Decis Mak. 2014 Jun 06;14:48. PubMed PMID: 24906941; PubMed Central PMCID: PMCPMC4067630. eng.

[27] Bartholomeeusen S, Kim CY, Mertens R, et al. The denominator in general practice, a new approach from the Intego database. Fam Pract. 2005 Aug;22 (4):442-447. PubMed PMID: 15964863; eng.

[28] Flamaing J. Vaccinaties en ouderen: stand van zaken. Tijdschrift Voor Geneeskunde. 2005;61(24):1751.

[29] Tafforeau J. Vaccinatie. In: Demarest S, Charafeddine R, editors. Gezondheidsenquête 2013. Rapport 5: preventie. Brussel: WIV-ISP; 2015:125-207.

[30] Bayas J-M, Izquierdo C, Ruiz L, et al. Validity of self-reported pneumococcal vaccination status in the elderly in Spain. Vaccine. 2009;27(34):4560-4564.
[31] Grimaldi-Bensouda L, Aubrun E, Leighton P, et al. Agreement between patients' self-report and medical records for vaccination: the PGRx database. Pharmacoepidemiol Drug Saf. 2013;22(3):278-285.

[32] Kroneman MW, van Essen GA, Tacken MA, et al. Does a population survey provide reliable influenza vaccine uptake rates among high-risk groups? A case-study of The Netherlands. Vaccine. 2004;22(17):2163-2170.

[33] Llupià A, García-Basteiro AL, Mena G, et al. Vaccination behaviour influences self-report of influenza vaccination status: a cross-sectional study among health care workers. PloS One. 2012;7(7):e39496.

[34] Mangtani P, Shah A, Roberts J. Validation of influenza and pneumococcal vaccine status in adults based on self-report. Epidemiol Infect. 2007;135(1):139-143.

[35] Wagenvoort GH, Knol MJ, de Melker HE, et al. Risk and outcomes of invasive pneumococcal disease in adults with underlying conditions in the post-PCV7 era, The Netherlands. Vaccine. 2016 Jan 12;34(3):334-340. PubMed PMID: 26647289; eng.

[36] Selya-Hammer C, Fleming D, Jiang $Y$, et al. Coadministration of PPV23 and influenza vaccines in England and Wales: a study based on the royal college of general practitioners sentinel surveillance network. J Vaccines Immun. 2015;1(2):043. 49:043.

[37] Castiglia P. Recommendations for pneumococcal immunization outside routine childhood immunization programs in Western Europe. Adv Ther. 2014 Oct;31(10):1011-1044. PubMed PMID: 25300593; PubMed Central PMCID: PMCPMC4209094. eng.

[38] Hak E, Rovers MM, Kuyvenhoven MM, et al. Incidence of GP-diagnosed respiratory tract infections according to age, gender and high-risk co-morbidity: the second Dutch national survey of general practice. Fam Pract. 2006 Jun;23(3):291-294. PubMed PMID: 16464869; eng.

[39] Millett ER, Quint JK, Smeeth L, et al. Incidence of community-acquired lower respiratory tract infections and pneumonia among older adults in the United Kingdom: a population-based study. PLoS One. 2013;8(9):e75131. PubMed PMID: 24040394; PubMed Central PMCID: PMCPMC3770598. eng.

[40]. Mocke L, Höffken G, Schmitt J. et al. Burden of ambulatory and hospitalized community-acquired pneumonia: a population based study in Germany. A62. CLINICAL ASPECTS OF CAP, HCAP, HAP, AND VAP. Am Thoracic Soc. 2016(193):A2087.

[41] Unit B. The incidence rate and economic burden of community-acquired pneumonia in a working-age population; 2013.

[42] Welte T, Torres A, Nathwani D. Clinical and economic burden of community-acquired pneumonia among adults in Europe. Thorax. 2012 Jan;67(1):71-79. PubMed PMID: 20729232; eng.

[43] Lipsitch $M$, Jha A, Simonsen L. Observational studies and the difficult quest for causality: lessons from vaccine effectiveness and impact studies. Int J Epidemiol. 2016 Dec 01;45(6):2060-2074. PubMed PMID: 27453361; eng.

[44] Simonsen L, Taylor RJ, Viboud C, et al. Mortality benefits of influenza vaccination in elderly people: an ongoing controversy. Lancet Infect Dis. 2007 Oct;7 (10):658-666. PubMed PMID: 17897608; eng. 
[45] van Vugt SF, Verheij TJ, de Jong PA, et al. Diagnosing pneumonia in patients with acute cough: clinical judgment compared to chest radiography. Eur Respir J. 2013 Oct;42(4):1076-1082. PubMed PMID: 23349450.

[46] Bello S, Menendez R, Torres A, et al. Tobacco smoking increases the risk for death from pneumococcal pneumonia. Chest. 2014 Oct;146(4):1029-1037. PubMed PMID: 24811098; eng.

[47] Hoeck S, van der Heyden J, Geerts J, et al. Preventive care use among the Belgian elderly population: does socio-economic status matter? Int J Environ Res Public Health. 2014 Jan;11(1):355-372. PubMed PMID: 24368427; PubMed Central PMCID: PMCPMC3924448.

\section{Appendices}

Appendix A. ICPC codes used for comorbidities

Appendix B. Proportion of adult patients at risk in 2015 and age group (4 age groups) $(\mathrm{N}=100,484)$

\begin{tabular}{|c|c|c|}
\hline High risk patients & $\begin{array}{l}\text { AIDS (B90) } \\
\text { Lymphoma (B72) } \\
\text { Leukemia (B73) } \\
\text { Malignant neoplasm (B74) } \\
\text { Immunosuppressant (ATC L04) } \\
\text { Glucocorticoids (ATC H02AB) }\end{array}$ & $\begin{array}{l}\text { Ever diagnosed before } 31 / 12 / 2015 \\
\text { diagnosed between } 01 / 01 / 2010 \text { and } 31 / 12 / 2014 \text { ( } 5 \text { years) } \\
\text { diagnosed between } 01 / 01 / 2010 \text { and } 31 / 12 / 2014 \text { (5 years) } \\
\text { diagnosed between } 01 / 01 / 2010 \text { and } 31 / 12 / 2014 \text { (5 years) } \\
\text { in } 2014 \text { or in } 2015 \\
\text { at least } 2 x \text { in } 2015\end{array}$ \\
\hline Median risk patients & $\begin{array}{l}\text { Chronic bronchitis (R79): } \\
\text { Congenital respiratory anomaly (R89): } \\
\text { COPD (R95): } \\
\text { Asthma (R96): } \\
\text { Congenital cardiovascular anomaly (K73): } \\
\text { Angina pectoris (K74): } \\
\text { Acute myocardial infarction (K75): } \\
\text { Chronic ischemic heart disease (K76 } \\
\text { Heart failure (K77): } \\
\text { Atrial fibrillation (K78 } \\
\text { Pulmonary heart disease (K82): } \\
\text { Heart valve disease (K83): } \\
\text { TIA (K89): } \\
\text { CVA (K90): } \\
\text { Peripheral arterial disease (K92): } \\
\text { Chronic liver disease (D97): } \\
\text { Chronic kidney disease eGFR<60 mL/min: } \\
{ }^{*} \text { Chronic alcohol abuse (P15) }\end{array}$ & $\begin{array}{l}\text { Ever diagnosed before } 31 / 12 / 2015 \\
\text { Ever diagnosed before } 31 / 12 / 2015 \\
\text { Ever diagnosed before } 31 / 12 / 2015 \\
\text { Ever diagnosed before } 31 / 12 / 2015 \\
\text { Ever diagnosed before } 31 / 12 / 2015 \\
\text { Diagnosed in } 2014 \text { or in } 2015 \\
\text { Ever diagnosed before } 31 / 12 / 2015 \\
\text { Ever diagnosed before } 31 / 12 / 2015 \\
\text { Ever diagnosed before } 31 / 12 / 2015 \\
\text { Ever diagnosed before } 31 / 12 / 2015 \\
\text { Ever diagnosed before } 31 / 12 / 2015 \\
\text { Ever diagnosed before } 31 / 12 / 2015 \\
\text { Ever diagnosed before } 31 / 12 / 2015 \\
\text { Ever diagnosed before } 31 / 12 / 2015 \\
\text { Ever diagnosed before } 31 / 12 / 2015 \\
\text { Ever diagnosed before } 31 / 12 / 2015 \\
\text { One measure }<60 \text { in } 2013 \text { or } 2014 \\
\text { Ever diagnosed before } 31 / 12 / 2015\end{array}$ \\
\hline Low risk patients & All the other patients in the yearly contact group 2015 & \\
\hline
\end{tabular}




\begin{tabular}{|c|c|c|c|c|c|}
\hline Risk group & Total population & $18-49$ years & $50-64$ years & $65-84$ years & $85+$ years \\
\hline High risk group, $n$ & 2089 & 636 & 663 & 707 & 83 \\
\hline Aids, $\mathrm{n}(\%)$ & $105(5.0)$ & $78(12.3)$ & $26(3.9)$ & $1(0.1)$ & $0(0.0)$ \\
\hline Lymphoma, n (\%) & $141(6.7)$ & $46(7.2)$ & $36(5.4)$ & $51(7.2)$ & $8(9.6)$ \\
\hline Leukemia, n (\%) & $133(6.4)$ & $49(7.7)$ & $48(7.2)$ & $32(4.5)$ & $4(4.8)$ \\
\hline Malignant neoplasm blood other, $\mathrm{n}(\%)$ & $55(2.6)$ & $7(1.1)$ & $20(3.0)$ & $22(3.1)$ & $6(7.2)$ \\
\hline Immunosuppressant, n (\%) & $488(23.4)$ & $191(30.0)$ & $169(25.5)$ & $122(17.3)$ & $6(7.2)$ \\
\hline Glucocorticoids, n (\%) & $1251(59.9)$ & $281(44.2)$ & 395 (59.6) & $514(72.7)$ & $61(73.5)$ \\
\hline Median risk group, $n$ & 23,916 & 6983 & 6440 & 8272 & 2221 \\
\hline Chronic bronchitis, n (\%) & $852(3.6)$ & $232(3.3)$ & $224(3.5)$ & $326(3.9)$ & $70(3.2)$ \\
\hline Congenital respiratory anomaly, n (\%) & $18(0.1)$ & $7(0.1)$ & $3(0.0)$ & $8(0.1)$ & $0(0.0)$ \\
\hline COPD, n (\%) & $2438(10.2)$ & $260(3.7)$ & $760(11.8)$ & $1162(14.0)$ & $256(11.5)$ \\
\hline Asthma, n (\%) & $9894(41.4)$ & $4598(65.8)$ & $2751(42.7)$ & $2252(27.2)$ & $293(13.2)$ \\
\hline Congenital cardiovascular anomaly, n (\%) & $295(1.2)$ & $167(2.4)$ & $61(0.9)$ & $58(0.7)$ & $9(0.4)$ \\
\hline Angina pectoris, $\mathrm{n}(\%)$ & $242(1.0)$ & $27(0.4)$ & $68(1.1)$ & $122(1.5)$ & $25(1.1)$ \\
\hline Acute myocardial infarction, $\mathrm{n}(\%)$ & $2288(9.6)$ & $393(5.6)$ & $711(11)$ & $945(11.4)$ & $239(10.8)$ \\
\hline Chronic ischemic heart disease, $\mathrm{n}(\%)$ & $1459(6.1)$ & $116(1.7)$ & $354(5.5)$ & $785(9.5)$ & $204(9.2)$ \\
\hline Heart failure, $\mathrm{n}(\%)$ & $971(4.1)$ & $37(0.5)$ & $98(1.5)$ & $481(5.8)$ & $355(16.0)$ \\
\hline Atrial fibrillation, n (\%) & $2466(10.3)$ & 99 (1.4) & $326(5.1)$ & $1400(16.9)$ & $641(28.9)$ \\
\hline Pulmonary heart disease, $\mathrm{n}(\%)$ & $203(0.8)$ & $10(0.1)$ & $17(0.3)$ & $120(1.5)$ & $56(2.5)$ \\
\hline Heart valve disease, $\mathrm{n}(\%)$ & $1778(7.4)$ & $204(2.9)$ & $358(5.6)$ & $894(10.8)$ & $322(14.5)$ \\
\hline TIA, n (\%) & $1008(4.2)$ & $37(0.5)$ & $145(2.3)$ & $547(6.6)$ & $279(12.6)$ \\
\hline CVA, n (\%) & $1996(8.3)$ & $270(3.9)$ & $505(7.8)$ & $858(10.4)$ & $363(16.3)$ \\
\hline Peripheral arterial disease, $\mathrm{n}(\%)$ & $1926(8.1)$ & $243(3.5)$ & $454(7.0)$ & 969 (11.7) & $260(11.7)$ \\
\hline Chronic liver disease, $\mathrm{n}(\%)$ & $2055(8.6)$ & $373(5.3)$ & 731 (11.4) & $818(9.9)$ & $133(6.0)$ \\
\hline Chronic kidney disease, $\mathrm{n}(\%)$ & $3786(15.8)$ & $113(1.6)$ & $493(7.7)$ & $2192(26.5)$ & $988(44.5)$ \\
\hline Chronic alcohol abuse, $\mathrm{n}(\%)$ & $1905(8.0)$ & $671(9.6)$ & 766 (11.9) & $442(5.3)$ & $26(1.2)$ \\
\hline Low risk patients, $n$ & 74,479 & 45,205 & 17,152 & 6377 & 3953 \\
\hline
\end{tabular}

